\title{
Ronin and Caspases in Embryonic Stem Cells: A New Perspective on Regulation of the Pluripotent State
}

\author{
T.P. ZWAKA \\ Baylor College of Medicine, Houston, Texas 77030
}

\begin{abstract}
Described here are recent discoveries in my laboratory which suggest that the complement of factors needed to direct ES cell pluripotency may be considerably larger than originally thought and may include proteins that act independently of the canonical factors described thus far. They also provide insight into a novel screening method that could be used to accelerate the identification and characterization of such factors.
\end{abstract}

Embryonic stem (ES) and ES-like cells afford attractive model systems for unraveling the complex molecular networks that give rise to cellular identity (Evans and Kaufman 1981; Martin 1981; Thomson et al. 1998). They are relatively easy to generate and maintain in culture and are amenable to a broad range of manipulations, including the creation of site-specific mutations in particular genes, with the use of a growing repertoire of molecular research tools now in the hands of cell biologists (Thomas and Capecchi 1987; Zwaka and Thomson 2003). More importantly, ES cells have the property of pluripotency, meaning that they can differentiate to any cell type in the body, even to germ cells (Pedersen 1986). Several groups now believe that a small core set of regulatory factors, including Pou5f1 (encoding the Oct4 protein), Sox2, and Nanog, maintain ES cells in the pluripotent state by acting on a limited number of target genes (for review, see Jaenisch and Young, 2008). This fundamental concept has generated enormous excitement in the biomedical research community, leading to successful reprogramming of somatic cells to an ES-like state (Takahashi and Yamanaka 2006; Yu et al. 2006; Okita et al. 2007; Takahashi et al. 2007; Wernig et al. 2007; Lowry et al. 2008; Park et al. 2008). This advancement was not serendipitous but represents the culmination of a long series of studies, such as somatic cell nuclear transfer (SCNT), to understand how the body's different cell lineages emerge from embryonic tissue (for review, see Boyer et al. 2006). Given the complexity of any cellular state, it is difficult to comprehend in detail even a single genetic network that is needed to guide cells smoothly from one cellular state to another. Thus, novel strategies must be identified that will allow identification of the pivotal components that maintain or alter stem cell states at one of more levels. Here, I describe recent discoveries in my laboratory which suggest that the complement of factors needed to direct ES cell pluripotency may be considerably larger than originally thought and may include proteins that act independently of the canonical factors described thus far (Dejosez et al. 2008; Fujita et al. 2008). They also provide insight into a novel screening method that could be used to accelerate the identification and characterization of such factors.

\section{CASPASES AS MEDIATORS OF ES CELL DIFFERENTIATION}

We have discovered that members of a specific family of enzymes (caspases), previously thought to be involved only in programmed cell death (Thornberry and Lazebnik 1998; Earnshaw et al. 1999), have an unexpected role in ES cell differentiation by disabling one of the transcriptional pathways responsible for ES cell pluripotency (Fujita et al. 2008). Thus, ES cells may use apoptotic elements not only to regulate their pool size and maintain their genomic integrity, but also to induce a shift from self-renewal to differentiation in response to specific extrinsic cues (Fig. 1). This hypothesis is of fundamental importance, because programmed cell death is typically viewed as an isolated process restricted to the removal of damaged or unnecessary cells. One of the reasons for this separation is that most cell biologists have focused on differentiated cell types, including tumor cell lines with only one lineage choice, in contrast to stem cells, with multiple lineage options.

With the notable exceptions of caspases 1 and 11, which are involved in inflammation, caspases have been assigned primary functions in apoptosis, with scant attention paid to their possible involvement in nonapoptotic pathways (Thornberry and Lazebnik 1998). Recently, however, investigators have identified contexts in which caspase activity is associated with processes other than cell death. In mouse erythroid precursor cells, for example, the activation of cell death receptors triggers caspase activation and subsequent inhibition of differentiation via cleavage of the differentiation-promoting transcription factor Gata-1, and treatment of these cells with caspase inhibitors promotes differentiation (De Maria et al. 1999a,b). Another report links caspases directly to the differentiation decisions of hematopoietic stem cells via effects on pathways such as that driven by the interleukins (Janzen et al. 2008). 


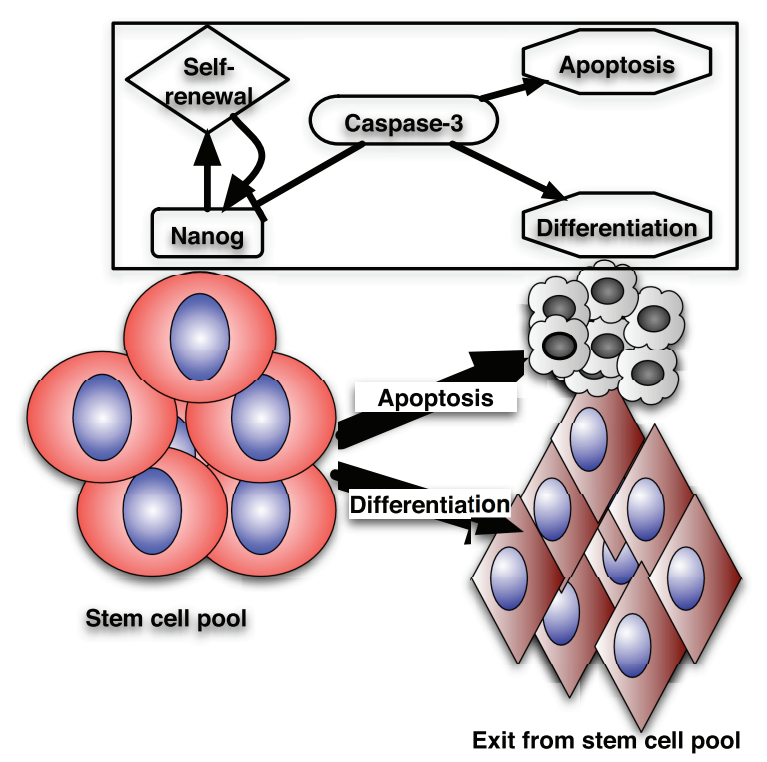

Figure 1. Stem cells can exit the stem cell pool either by differentiation or apoptosis. We found that caspase-3, previously known to be only essential for apoptosis, has a role in differentiation by cleaving Nanog and therefore allowing ES cells to exit the self-renewal cycle.

Further examples of processes that recruit caspases for purposes other than apoptosis include cell degradation or fusion during the differentiation of specific blood lineages (e.g., erythrocytes and megakaryocytes), the fusion of trophoblast-derived cells, the enucleation of keratinocytes and the lens epithelium, and sperm maturation (Ishizaki et al. 1998; De Botton et al. 2002; Arama et al. 2003; Fernando and Megeney 2007). Together, these observations support the notion that caspases can affect key developmental decisions, although the mechanisms and the nuances of context that induce these proteases into nonapoptotic pathways remain unclear.

Given the emerging reputation of caspases as posttranslational modifiers of mammalian cell development, we considered them to be attractive candidates for one of the mechanistic elements that allow ES cells to escape their self-renewal constraints and rapidly begin to generate developmentally committed progeny. To accommodate the capacity of these cells to undergo germ-layer-specific differentiation, we predicted that caspase-3 may negatively regulate core self-renewal factors such as Oct4, Sox2, and Nanog, based on a surprising increase in the activity of this enzyme after induction of differentiation. Indeed, further experiments demonstrated caspase-induced cleavage of Nanog in differentiating ES cells, whereas stem cells lacking the Casp3 gene displayed a marked defect in differentiation, and forced expression of a caspase-cleavage-resistant Nanog mutant in ES cells strongly promoted self-renewal (Fujita et al. 2008). We also found that in certain contexts, caspase-3 cooperates with caspase-9 to deactivate Nanog (Fujita et al. 2008). These findings suggest that ES cells exploit caspase- 3 and -9 and perhaps others for rapid and spe- cific deactivation of Nanog, thus disrupting the autoregulatory circuit that preserves the pluripotent state in these cells (Boyer et al. 2005).

\section{RONIN, A CANDIDATE PLURIPOTENCY FACTOR WITH DISTINCT FUNCTIONS}

Despite recent remarkable progress in reprogramming somatic cells to an ES-like state (induced pluripotent stem or iPS cells) via the manipulation of several key transcription factors (Takahashi and Yamanaka 2006; Yu et al. 2006; Okita et al. 2007; Takahashi et al. 2007; Wernig et al. 2007; Lowry et al. 2008; Park et al. 2008), the molecular mechanisms underlying the pluripotent state have only begun to emerge. The key regulators of ES cell pluripotency appear to be a small set of specific transcription factors able to promote self-renewal by repressing the transcription factors that initiate differentiation (Boyer et al. 2005; Bernstein et al. 2006; Lee et al. 2006). Prominent among these factors are Oct4, Sox2, and Nanog (Nichols et al. 1998; Avilion et al. 2003; Chambers et al. 2003). Although each of these proteins has been described by different authors as a "master regulator" of pluripotency, only Oct4 appears to be absolutely essential, whereas both Sox 2 and Nanog are dispensable, at least in certain molecular contexts (Chambers et al. 2007; Masui et al. 2007). A second tier of pluripotency control is likely achieved via enzyme-mediated modification of chromatin (Klochendler-Yeivin et al. 2000; Loh et al. 2007; Fazzio et al. 2008). Thus, maintenance of the pluripotent state could require several different mechanisms acting in parallel and, potentially, even independently of one another. Given this background, and our finding that caspase-3 targets and cleaves Nanog upon induction of ES cell differentiation, we devised a yeast two-hybrid screen for other caspase-3 targets in ES cells, whose functions might augment the current repertoire of factors known to regulate the pluripotent state of ES cells. Constitutively modified caspase-3 spontaneously folds into its active conformation and recognizes and binds to target proteins, but no longer cleaves them due to a $\mathrm{C} 163 \mathrm{~S}$ substitution that was used as bait, in our two-hybrid screen because (1) unmodified procaspase- 3 is functionally inactive and (2) actual cleavage of targets would render the interaction screening analysis useless (Kamada et al. 1998). After screening approximately 32 million clones, we identified 556 yeast wells that were positive for interaction with caspase- 3 and selected a representative set of 286 positive wells for further study (Dejosez et al. 2008). Cognizant of the overwhelming number of proteins that could at least distantly be associated with pluripotency, we performed confirmation experiments that included an in vitro transcription/translation caspase-3 cleavage assay yielding cDNAs coding for proteins that were specific targets of caspase-3 or at least were associated with the protease. Among the inner circle of resultant genes was a cDNA encoding a protein that bore a striking resemblance to the Drosophila P-element transposase. Named Ronin (a masterless Japanese Samurai) to indicate its lack of any apparent relationship to known pluripotency factors, this protein possessed a THAP (thanatos-associated protein) domain at the amino terminus (Roussigne et al. 2003a,b; Macfarlan 2005; Quesneville et al. 2005) and 
therefore could be expected to participate in sequence-specific DNA binding and epigenetic silencing of gene expression, rendering it an attractive candidate for a role in ES cell development.

\section{STRUCTURAL FEATURES OF RONIN}

Ronin's THAP domain is remarkable in that is appears to be part of a "domesticated" DNA transposon. The Ronin gene located on chromosomes 16q22.1 and 8D3 in humans and mice, respectively, contains only one exon, suggesting that there is strong selective pressure against its interruption with introns. First characterized in 2003, the THAP domain is shared by numerous proteins across all animal species ( $\sim 200$ proteins with this domain have been identified so far) (Roussigne et al. 2003a,b). The THAP domain zinc-finger-containing DNA-binding protein motif is characterized by a $\mathrm{C} 2 \mathrm{CH}$ signature (Cys$\mathrm{Xaa}_{2-4}-\mathrm{Cys}-\mathrm{Xaa}_{33-50}-\mathrm{Cys}-\mathrm{X}-\mathrm{aa}_{2}$ ). Other essential residues are P26, W36, F38, and P78. The three cysteines and the histidine bind a central zinc atom, with the two $\beta$-sheets folded against one another while being separated by an amino acid chain that is unusually long for zinc fingers and contains an $\alpha$-helix that is partly responsible for the sequence specificity of DNA binding. In contrast to other zinc finger motifs, the THAP domain contains a second region of amino acids that is also important for DNA sequence-specific binding. It is located toward the end of the domain, which lies in the three-dimensional structure exactly parallel to the $\alpha$-helix (the sequence is AVPTIF) (Liew et al. 2007; Bessière et al. 2008). One of the most widely known members of the THAP domain family, the Drosophila P-element transposase, exhibits site-specific DNA binding to a consensus sequence at both the $5^{\prime}$ and $3^{\prime}$ regions of the transposase. The human genome contains 12 THAP-domain-containing proteins, of which only DAP4/p52rIPK, THAP1, and THAP7 have been characterized in detail (the mouse genome contains five THAPdomain-containing proteins). Caenorhabditis elegans expresses several important THAP proteins, including Lin-15b (Chesney et al. 2006) and Lin-36 (encoded by the class-B synthetic multivulva genes) (Clouaire et al. 2005), CDC-14B and CTB-1 (an ortholog of CtBP-1), all of which are involved in transcriptional control, and the protein HIM-17 (Reddy and Villeneuve 2004), which is involved in meiotic recombination and recruitment of the methyltransferase activity of histone $\mathrm{H} 3$ at lysine 9. Evidence for active DNA transposons containing a THAP domain has been obtained in zebra fish, and it is clear that this class of transposons was "domesticated" in a common ancestor of birds and mammals (Hammer et al. 2005; Quesneville et al. 2005). The most likely explanation for the wide distribution of THAP-containing protein domains across animal species is that they initially formed as a result of exon shuffling after DNA transposition of the first exon (containing the THAP domain) into other genes. These genes then acquired the DNA-binding activity of the DNA transposon and evolved further. It should be noted that this "domestication" of selfish DNA elements has precedence in evolutionary history; the most famous example is a DNA transposase that became the RAG-
1/RAG-2 DNA recombination protein in mammals (Hammer et al. 2005; Quesneville et al. 2005).

Like most other THAP-domain-containing proteins, Ronin contains this motif at the amino terminus, followed by a polyglutamine stretch of 29 glutamine residues. These residues are encoded by CAGs occasionally interrupted by CAAs, suggesting that this repetitive sequence possesses at least some stability. Because glutamine chains of this size ( $\sim 30$ amino acids) are known to be relatively stiff, this conformation suggests that the polyglutamine tract separates the DNA-binding activity from the function of the carboxyl terminus.

\section{RONIN EXPRESSION PATTERN DURING DEVELOPMENT}

We searched for expression of Ronin in mouse and human ES cells and were able to detect its expression at the RNA level in the form of an approximately $1.8-\mathrm{kb}$ transcript. Using a series of antibodies, we were successful in detecting Ronin protein in tissue sections and in cells stained in vitro. In the adult mouse, Ronin expression was mostly restricted to ovary and testes. Antibody staining of the ovary revealed high levels of Ronin in the ooplasm, although equal distribution of the protein was found across the entire oocyte after ovulation. We could not identify lacZ-positive cells in any of the adult organs tested (including brain, lung, thymus, heart, liver, gastrointestinal tract, bone marrow, skeletal muscle, and skin). We therefore concluded that Ronin expression is likely restricted to the earliest stages of development. Indeed, further antibody testing detected significant amounts of Ronin in the fertilized zygote. The lacZ reporter mouse lines showed increased Ronin expression in the inner cell mass of the blastocyst, whereas analysis of E8.5 and E10.5 embryos revealed substantial staining in specific organs such as the genital ridge, the heart, and the central nervous system, suggesting a specific role for Ronin during these phases of development. Importantly, gene expression studies with an inducible cell line showed that Ronin is exclusively a nuclear protein. It did not colocalize with DAPI (4'-6-diamidino-2-phenylindole)stained areas in the nucleus or with polymerase II, indicating that it is primarily localized in silent regions of the genome. These findings contrast with the detection of Ronin in the cytoplasm during other stages of development, underscoring the complexity of its expression pattern and the need for a more detailed analysis of this feature in the future.

\section{RONIN KNOCKOUT INDUCES LETHAL DEFECTS IN PRE-AND PERI-IMPLANTATION EMBRYOS}

We created a Ronin knockout mouse by gene targeting. Although none of the pups or E10.5 and E7.5 embryos were Ronin $^{-1-}$, we did find a substantial number of empty deciduas on day E7.5, suggesting that a decidua formation was initiated but did not result in an embryo. In contrast, a proportion of the E3.5 embryos (blastocysts) had a Ronin ${ }^{-1}$ genotype. These blastocysts lacked obvious morphologic 
defects, and TUNEL (terminal deoxynucleotidyl-mediated nick-end labeling) staining did not detect an increase in apoptotic cells. To test the outgrowth potential of the inner cell mass, we placed the embryos in plastic dishes with medium derived from ES cell cultures. Whereas a significant majority of Ronin $^{+/}$and Ronin $^{+/+}$embryos were able to attach and formed the typical flattened trophoblast epithelium and the inner cell mass, Ronin ${ }^{-/}$blastocyst formed only the trophectoderm layer, suggesting a severe defect in outgrowth of the inner cell mass. Although this deficiency could be attributed to an abnormality in the trophoblastic cells leading to failure to support the inner cell mass, we argue against this interpretation because Ronin is not expressed in trophoblastic cells and its knockout in ES cells is lethal. Thus, Ronin appears to be essential for normal mammalian development but only during its earliest stages.

\section{ECTOPIC EXPRESSION OF RONIN IN ES CELLS INDUCES A DIFFERENTIATION DEFECT AND GLOBAL TRANSCRIPTIONAL REPRESSION}

We also generated a novel mouse ES cell line that ectopically expresses Ronin under a constitutive promoter. We noticed that such ES cells possess essentially the same morphology as that of normal ES cells but typically failed to differentiate in vitro and in immunocompromised mice. This antidifferentiation effect of Ronin is analogous to the ability of Nanog to promote self-renewal under unfavorable conditions (Chambers et al. 2003) and is observed in vitro only when ES cells are grown in the absence of leukemia-inhibitory factor (LIF), an essential factor for self-renewal that triggers signaling through the STAT (signal transducer and activator of transcription) factor. Ronin can substitute for the LIF-STAT pathway in ES cell cultures, even over two passages when the ES cells are propagated at clonal densities, similar to Nanog.

The nature of the differentiation defect in ES cells overexpressing Ronin was unclear, prompting us to perform microarray studies of ES cells with only transient expression of Ronin. This experiment revealed a striking shift in the expression of many genes, some of which have recognized functions in development, whereas measurement of newly synthesized RNA levels after induction of Ronin expression indicated pronounced decreases in the expression of key developmental genes. Thus, Ronin could be involved in the control of RNA transcription of multiple genes with roles in cell differentiation. This repressive activity could be exerted by binding directly to DNA or, as indicated by our protein-protein interaction data, by directly recruiting HCF-1 and subsequently other proteins with the ability to modify chromatin, such as mixed-lineage leukemia (MLL), Set1 (histone H3K4 methyltransferase), Sin3, histone deacetylase (HDAC), and histone acetyltransferase (HAT) (previously associated with chromatin modification) (Wysocka et al. 2003; Yokoyama et al. 2004), to sites of specific genes contributing to ES cell differentiation. The exact manner in which this putative protein complex suppresses gene transcription is unclear. In addition to its role as a transcriptional repressor, $\mathrm{HCF}-1$ has been linked to regulation of the cell cycle; however, both acute and chronic expression of Ronin in ES cells as well as somatic cells have at most only a marginal effect on the proliferation of ES cells, making it unlikely that the interaction of Ronin with HCF-1 contributes to cell cycle control.

\section{WHAT DOES RONIN TEACH US ABOUT PLURIPOTENCY?}

A very elegant concept of pluripotency is that of a default state whereby a core set of transcription factors controls both the transcriptional and epigenetic landscape (Boyer et al. 2006). This would imply that pluripotency occurs by default and in a hierarchical fashion when these "core" transcription factors activate other transcription factors, as well as epigenetic modifiers that control the pluripotent state. This theory is supported by the finding that specific epigenetic factors, such as the histone demethylases Jmjd1a and Jmjd2c, are essential for pluripotency and transcriptionally regulated by Oct4 (Loh et al. 2007). This transcription-factor-centric hierarchical model is further corroborated by the recent discovery that forced expression of Oct4, Sox2, Klf4, and c-Myc in differentiated cells leads to a pluripotent state similar to that in ES cells. Although this concept is attractive, it focuses entirely on Oct4/Sox 2 as the main axis of pluripotency and discounts numerous biological examples showing that particular states are often established and maintained by independent pathways in parallel. Thus, one could predict the existence of pluripotency factors (either transcription factors or epigenetic modulators) that are (1) not directly downstream from the known core pluripotency factor genes (Oct4, Sox2, and Nanog) and do not positively affect their expression and (2) still essential and even sufficient to sustain pluripotency. We suggest that our newly identified factor, Ronin, belongs in this category and may represent an entirely different mechanism by which pluripotency could be achieved and maintained (Fig. 2).

The expression pattern of Ronin shows some major differences compared to those of the other pluripotency factors, including Oct4, Nanog, and Sox2. Ronin is clearly expressed during the earliest stages of development, but it does not disappear rapidly at the blastocyst stage. Indeed, we detected Ronin expression in the adult ovary and, more interestingly, in the hippocampus, olfactory region, subventricular zone, and cerebellum of the adult brain, suggesting specific roles in these regions. Thus, we propose that Ronin is expressed in specific cells during development and in the adult, where it is either required to fulfill roles analogous to those during early embryonic development or has distinct functions that remain undefined. Expression of Ronin, at least in the brain, indicates that the protein participates in other stem cell/progenitor systems, a concept that has been applied to the zinc finger protein Zfx (Galan-Caridad et al. 2007; Chen et al. 2008). The hypothesis that Ronin is expressed in stem cell progenitor populations in the developing embryo requires further investigation.

Numerous issues concerning the functional roles of Ronin remain unresolved. For instance, the protein appears to recognize and bind to DNA in a specific manner, but its mechanism of action is still undefined. Several members of the THAP protein family regulate cells at the 


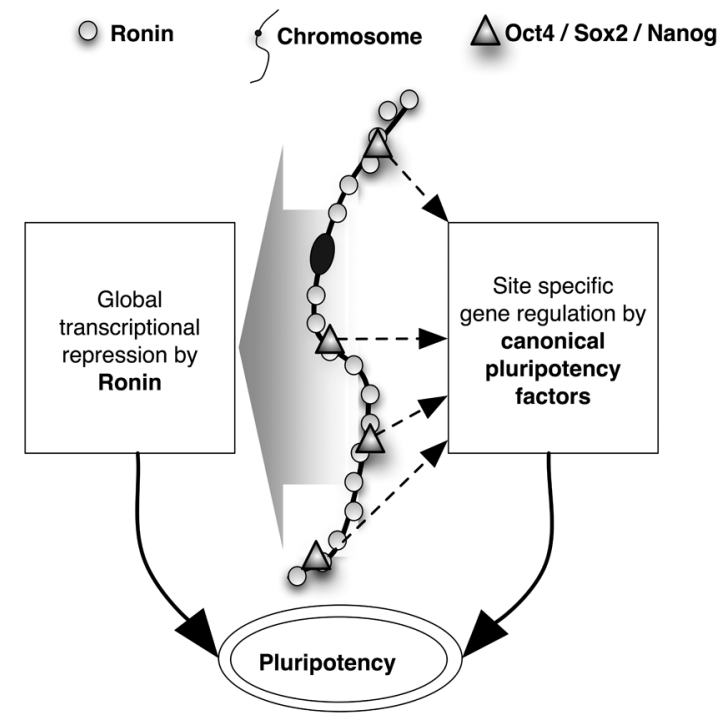

Figure 2. Proposed model for the mechanism of Ronin function. In contrast to the site-specific gene modulatory activity of canonical pluripotency factors (e.g., Oct4, Sox2, and Nanog), Ronin appears to repress transcription more broadly to ensure the maintenance of ES cell pluripotency. (Reprinted from Dejosez et al. 2008 [C Cell Press].)

epigenetic level (Reddy and Villeneuve 2004; Macfarlan 2005; Macfarlan et al. 2005), suggesting that epigenetic silencing of gene expression is a function of Ronin as well. It will be important to distinguish between these two functions in future efforts to explain the mechanisms by which Ronin sustains pluripotency. Finally, because our discovery of Ronin has several implications for studies of pluripotency, as mentioned earlier, the full repertoire of factors involved in establishing or maintaining pluripotency, or in reprogramming somatic cells to an ES-like state, is unknown. In our opinion, focusing exclusively on gene expression profiles is unlikely to close this gap in the near future, whereas screening cDNA libraries for candidate factors, using a fundamental strategy as outlined in this chapter, could yield much more rapid insights into the constituent molecules of pluripotency pathways.

\section{TOWARD UNDERSTANDING CELLULAR IDENTITY}

Deciphering the transcription factor code underlying particular cellular states will be essential for experimentally changing these states and attempting to understand naturally occurring transitions during development and in the adult organism. Perhaps the most significant impact of identifying new caspase targets such as Nanog and Ronin is that it provides a much-needed window into the complexity of transcriptional networks that give rise to cellular identity and increases the set of cell-fate-determining transcription factors that could be introduced into mammalian cells to reprogram them to the phenotype of another cell type. The most extreme form of such cellular "shape shifting" was the recent demonstration that well- differentiated cells, such as fibroblasts, could be reprogrammed to a state akin to that of ES cells, the most primitive cell type sustainable in cell culture. The practical implications of using trans-differentiation or reprogramming factors to change cellular identities in any direction are enormous and most likely will revise the research directions of many different fields of biology. Equally critical is the potential impact of these discoveries on our comprehension of how cells differ from one another and why most cells retain their identity for very long periods of time without appreciable changes. It is not unreasonable to predict that the new understanding of cellular identity will enhance our ability to produce therapeutically relevant cell types that could be administrated to a broad range of patients whose diseases reflect malfunctions in the cellular circuitry regulating large blocks of gene expression. An obvious question that must be addressed before the promises of the genetic reprogramming can be realized is whether the emerging observations on control of the pluripotent state are in fact relevant to the developing embryo and the adult organism or merely phenomena induced by the introduction of artificial factors.

At the conceptional level, it is intriguing to consider transcription-factor-mediated shifts in cell lineages in the context of another compelling theory, epigenetic ground states. The epigenetic ground state has its roots in experimental observations of epigenetic marks, in particular K4 and K27 histone methylation and DNA methylation, and the observation that some of these epigenetic marks can be found in association with specific DNA sequences in undifferentiated ES cells (Bernstein et al. 2006). The prediction is that discrete genomic DNA sequences specifically encode signatures that can be recognized by epigenetic factors that then impose specific epigenetic alterations (Bernstein et al. 2007). An obvious extension of this idea is that there are specific determinants in the genome not only for pluripotent undifferentiated cells, but eventually also for every cellular state in the body. Specific subsets of cell-type-specific transcription factors could therefore be expected to initiate the transcriptional program that imposed the epigenetic changes associated with a particular cellular state or developmental stage. This model is analogous to a holographic image where every point of the image contains the information of the entire image, even though only one perspective is revealed to the viewer, depending on the angle of the laser light. Thus, just as a change in light angle produces a change in the holograph, different sets of transcription factors could be expected to induce a different phenotype, even though all cells store the same genetic information. If multiple ground states are indeed responsible for cellular identities, and if these states are determined by specific transcriptional programs, then one could reasonably postulate the existence of master regulators that dictate cellular identity. Logically then, such regulators would be capable of overriding preexisting cellular states at least under certain circumstances. Even though such transitions are still purely theoretical, their experimental confirmation would challenge the fundamental dogma of developmental biology: lineage linearity throughout development, whereby cells imperatively transit through specific stages that dictate subsequent cell fates through the expression of morphogens or 


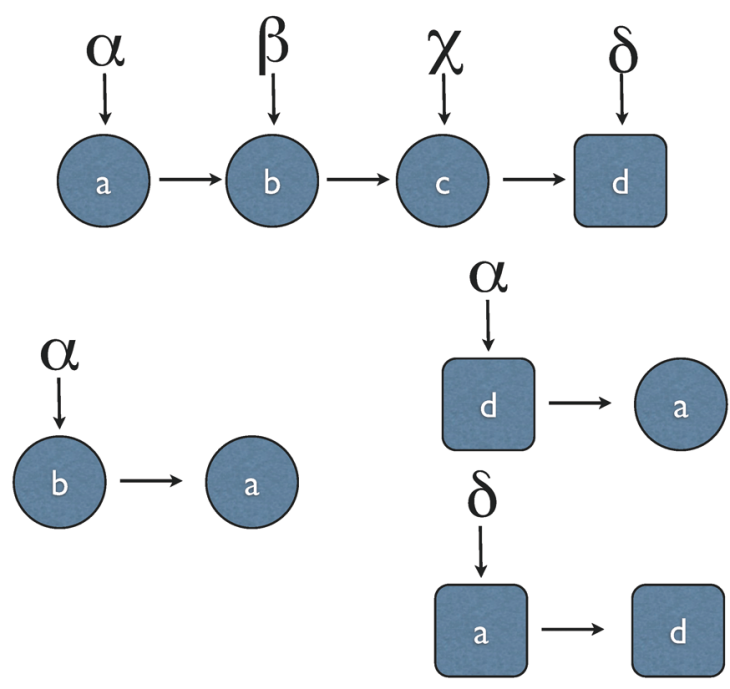

Figure 3. Until now, we have assumed that a developing and differentiating cell goes through different and defined steps to terminally differentiate $(a-d)$, that a specific cascade of transcription and epigenetic factors allows progression to the next step, and that the order of steps is critical for successful differentiation. However, the fact that cells can "jump" from a state of terminal differentiation to one of complete undifferentiation indicates that the concept of lineage linearity can be bypassed, at least artificially in the laboratory. According to this concept, master regulators $(\alpha, \beta, \chi$, and $\delta)$ can dictate the cellular state.

other developmental factors. We would argue that developmental linearity and sequentiality, while appearing critical for morphogenesis, are not necessarily a requirement for cellulogenesis, in which master transcriptional regulators and epigenetic ground states could have the central role (Fig. 3). Hence, the most challenging task for the future will be to devise novel strategies that could be used to identify critical regulatory factors at any given step in the acquisition of cellular identity. We believe that our discovery of caspases as regulatory elements specifically targeting transcription factors involved in the shaping of cellular identities is an important first step in this direction.

\section{ACKNOWLEDGMENTS}

The author is supported by the Diana Helis Henry Medical Research Foundation, the Huffington Foundation, and the National Institutes of Health.

\section{REFERENCES}

Arama, E., Agapite, J., and Steller, H. 2003. Caspase activity and a specific cytochrome $\mathrm{C}$ are required for sperm differentiation in Drosophila. Dev. Cell 4: 687-697.

Avilion, A.A., Nicolis, S.K., Pevny, L.H., Perez, L., Vivian, N., and Lovell-Badge, R. 2003. Multipotent cell lineages in early mouse development depend on SOX2 function. Genes Dev. 17: 126-140.

Bernstein, B.E., Mikkelsen, T.S., Xie, X., Kamal, M., Huebert, D.J., Cuff, J., Fry, B., Meissner, A., Wernig, M., Plath, K., et al. 2006. A bivalent chromatin structure marks key developmental genes in embryonic stem cells. Cell 125: 315-326.

Bernstein, B.E., Meissner, A., and Lander, E.S. 2007. The mammalian epigenome. Cell 128: 669-681.
Bessière, D., Lacroix, C., Campagne, S., Ecochard, V., Guillet, V., Mourey, L., Lopez, F., Czaplicki, J., Demange, P., Milon, A., et al. 2008. Structure-function analysis of the THAP zinc finger of THAP1, a large C2CH DNA-binding module linked to Rb/E2F pathways. J. Biol. Chem. 283: 4352-4363.

Boyer, L.A., Lee, T.I., Cole, M.F., Johnstone, S.E., Levine, S.S., Zucker, J.P., Guenther, M.G., Kumar, R.M., Murray, H.L., Jenner, R.G., et al. 2005. Core transcriptional regulatory circuitry in human embryonic stem cells. Cell 122: 947-956.

Boyer, L.A., Mathur, D., and Jaenisch, R. 2006. Molecular control of pluripotency. Curr. Opin. Genet. Dev. 16: 455-462.

Chambers, I., Colby, D., Robertson, M., Nichols, J., Lee, S., Tweedie, S., and Smith, A. 2003. Functional expression cloning of nanog, a pluripotency sustaining factor in embryonic stem cells. Cell 113: 643-655.

Chambers, I., Silva, J., Colby, D., Nichols, J., Nijmeijer, B., Robertson, M., Vrana, J., Jones, K., Grotewold, L., and Smith, A. 2007. Nanog safeguards pluripotency and mediates germline development. Nature 450: 1230-1234.

Chen, X., Xu, H., Yuan, P., Fang, F., Huss, M., Vega, V.B., Wong, E., Orlov, Y.L., Zhang, W., Jiang, J., et al. 2008. Integration of external signaling pathways with the core transcriptional network in embryonic stem cells. Cell 133: 1106-1117.

Chesney, M.A., Kidd III, A.R., and Kimble, J. 2006. gon-14 functions with class $\mathrm{B}$ and class $\mathrm{C}$ synthetic multivulva genes to control larval growth in Caenorhabditis elegans. Genetics 172: 915-928.

Clouaire, T., Roussigne, M., Ecochard, V., Mathe, C., Amalric, F., and Girard, J.P. 2005. The THAP domain of THAP1 is a large $\mathrm{C} 2 \mathrm{CH}$ module with zinc-dependent sequence-specific DNAbinding activity. Proc. Natl. Acad. Sci. 102: 6907-6912.

De Botton, S., Sabri, S., Daugas, E., Zermati, Y., Guidotti, J.E., Hermine, O., Kroemer, G., Vainchenker, W., and Debili, N. 2002. Platelet formation is the consequence of caspase activation within megakaryocytes. Blood 100: 1310-1317.

Dejosez, M., Krumenacker, J.S., Zitur, L.J., Passeri, M., Chu, L.F., Songyang, Z., Thomson, J.A., and Zwaka, T.P. 2008. Ronin is essential for embryogenesis and the pluripotency of mouse embryonic stem cells. Cell 133: 1162-1174.

De Maria, R., Testa, U., Luchetti, L., Zeuner, A., Stassi, G., Pelosi, E., Riccioni, R., Felli, N., Samoggia, P., and Peschle, C. 1999a. Apoptotic role of Fas/Fas ligand system in the regulation of erythropoiesis. Blood 93: 796-803.

De Maria, R., Zeuner, A., Eramo, A., Domenichelli, C., Bonci, D., Grignani, F., Srinivasula, S.M., Alnemri, E.S., Testa, U., and Peschle, C. 1999b. Negative regulation of erythropoiesis by caspase-mediated cleavage of GATA-1. Nature 401: 489493.

Earnshaw, W.C., Martins, L.M., and Kaufmann, S.H. 1999. Mammalian caspases: Structure, activation, substrates, and functions during apoptosis. Annu. Rev. Biochem. 68: 383-424.

Evans, M.J. and Kaufman, M.H. 1981. Establishment in culture of pluripotential cells from mouse embryos. Nature 292: 154156.

Fazzio, T.G., Huff, J.T., and Panning, B. 2008. An RNAi screen of chromatin proteins identifies Tip60-p400 as a regulator of embryonic stem cell identity. Cell 134: 162-174.

Fernando, P. and Megeney, L.A. 2007. Is caspase-dependent apoptosis only cell differentiation taken to the extreme? FASEB J. 21: 8-17.

Fujita, J., Crane, A.M., Souza, M.K., Dejosez, M., Kyba, M., Flavell, R.A., Thomson, J.A., and Zwaka, T.P. 2008. Caspase activity mediates the differentiation of embryonic stem cells. Cell Stem Cell 2: 595-601.

Galan-Caridad, J.M., Harel, S., Arenzana, T.L., Hou, Z.E., Doetsch, F.K., Mirny, L.A., and Reizis, B. 2007. Zfx controls the self-renewal of embryonic and hematopoietic stem cells. Cell 129: 345-357.

Hammer, S.E., Strehl, S., and Hagemann, S. 2005. Homologs of Drosophila $\mathrm{P}$ transposons were mobile in zebrafish but have been domesticated in a common ancestor of chicken and human. Mol. Biol. Evol. 22: 833-844.

Ishizaki, Y., Jacobson, M.D., and Raff, M.C. 1998. A role for caspases in lens fiber differentiation. J. Cell Biol. 140: 153-158. 
Jaenisch, R. and Young, R. 2008. Stem cells, the molecular circuitry of pluripotency and nuclear reprogramming. Cell 132: 567-582.

Janzen, V., Fleming, H.E., Riedt, T., Karlsson, G., Riese, M.J., Lo Celso, C., Reynolds, G., Milne, C.D., Paige, C.J., Karlsson, S., et al. 2008. Hematopoietic stem cell responsiveness to exogenous signals is limited by caspase-3. Cell Stem Cell 2: 584 594.

Kamada, S., Kusano, H., Fujita, H., Ohtsu, M., Koya, R.C., Kuzumaki, N., and Tsujimoto, Y. 1998. A cloning method for caspase substrates that uses the yeast two-hybrid system: Cloning of the antiapoptotic gene gelsolin. Proc. Natl. Acad. Sci. 95: 8532-8537.

Klochendler-Yeivin, A., Fiette, L., Barra, J., Muchardt, C., Babinet, C., and Yaniv, M. 2000. The murine SNF5/INI1 chromatin remodeling factor is essential for embryonic development and tumor suppression. EMBO Rep. 1: 500-506.

Lee, T.I., Jenner, R.G., Boyer, L.A., Guenther, M.G., Levine, S.S., Kumar, R.M., Chevalier, B., Johnstone, S.E., Cole, M.F., Isono, K., et al. 2006. Control of developmental regulators by Polycomb in human embryonic stem cells. Cell 125: 301-313.

Liew, C.K., Crossley, M., Mackay, J.P., and Nicholas, H.R. 2007. Solution structure of the THAP domain from Caenorhabditis elegans C-terminal binding protein (CtBP). J. Mol. Biol. 366: 382-390.

Loh, Y.H., Zhang, W., Chen, X., George, J., and Ng, H.H. 2007. Jmjd1a and Jmjd2c histone H3 Lys 9 demethylases regulate self-renewal in embryonic stem cells. Genes Dev. 21: 2545 2557.

Lowry, W.E., Richter, L., Yachechko, R., Pyle, A.D., Tchieu, J., Sridharan, R., Clark, A.T., and Plath, K. 2008. Generation of human induced pluripotent stem cells from dermal fibroblasts. Proc. Natl. Acad. Sci. 105: 2883-2888.

Macfarlan, T. 2005. "Identification and initial characterization of thanatos associated protein 7 (THAP7), a putative transcriptional repressor." Ph.D. thesis. University of Pennsylvania, Philadelphia.

Macfarlan, T., Kutney, S., Altman, B., Montross, R., Yu, J., and Chakravarti, D. 2005. Human THAP7 is a chromatin-associated, histone tail-binding protein that represses transcription via recruitment of HDAC3 and nuclear hormone receptor corepressor. J. Biol. Chem. 280: 7346-7358.

Martin, G.R. 1981. Isolation of a pluripotent cell line from early mouse embryos cultured in medium conditioned by teratocarcinoma stem cells. Proc. Natl. Acad. Sci. 78: 7634-7638.

Masui, S., Nakatake, Y., Toyooka, Y., Shimosato, D., Yagi, R. Takahashi, K., Okochi, H., Okuda, A., Matoba, R., Sharov, A.A., et al. 2007. Pluripotency governed by Sox 2 via regulation of Oct3/4 expression in mouse embryonic stem cells. Nat. Cell Biol. 9: 625-635.

Nichols, J., Zevnik, B., Anastassiadis, K., Niwa, H., KleweNebenius, D., Chambers, I., Scholer, H., and Smith, A. 1998. Formation of pluripotent stem cells in the mammalian embryo depends on the POU transcription factor Oct4. Cell 95: 379 391.

Okita, K., Ichisaka, T., and Yamanaka, S. 2007. Generation of germline-competent induced pluripotent stem cells. Nature 448: 313-317.

Park, I.H., Zhao, R., West, J.A., Yabuuchi, A., Huo, H., Ince, T.A.,
Lerou, P.H., Lensch, M.W., and Daley, G.Q. 2008. Reprogramming of human somatic cells to pluripotency with defined factors. Nature 451: 141-146.

Pedersen, R.A. 1986. Potency, lineage and allocation in preimplantation mouse embryos. In Experimental approaches to mammalian embryonic development (ed. J. Rossant and R.A. Pedersen), pp. 3-33. Cambridge University Press, New York.

Quesneville, H., Nouaud, D., and Anxolabehere, D. 2005. Recurrent recruitment of the THAP DNA-binding domain and molecular domestication of the P-transposable element. Mol. Biol. Evol. 22: 741-746.

Reddy, K.C. and Villeneuve, A.M. 2004. C. elegans HIM-17 links chromatin modification and competence for initiation of meiotic recombination. Cell 118: 439-452.

Roussigne, M., Cayrol, C., Clouaire, T., Amalric, F., and Girard, J.P. 2003a. THAP1 is a nuclear proapoptotic factor that links prostate-apoptosis-response-4 (Par-4) to PML nuclear bodies. Oncogene 22: 2432-2442.

Roussigne, M., Kossida, S., Lavigne, A.C., Clouaire, T., Ecochard, V., Glories, A., Amalric, F., and Girard, J.P. 2003b. The THAP domain: A novel protein motif with similarity to the DNA-binding domain of $\mathrm{P}$ element transposase. Trends Biochem. Sci. 28: 66-69.

Takahashi, K. and Yamanaka, S. 2006. Induction of pluripotent stem cells from mouse embryonic and adult fibroblast cultures by defined factors. Cell 126: 663-676.

Takahashi, K., Tanabe, K., Ohnuki, M., Narita, M., Ichisaka, T., Tomoda, K., and Yamanaka, S. 2007. Induction of pluripotent stem cells from adult human fibroblasts by defined factors. Cell 131: 861-872.

Thomas, K.R. and Capecchi, M.R. 1987. Site-directed mutagenesis by gene targeting in mouse embryo-derived stem cells. Cell 51: 503-512.

Thomson, J.A., Itskovitz-Eldor, J., Shapiro, S.S., Waknitz, M.A., Swiergiel, J.J., Marshall, V.S., and Jones, J.M. 1998. Embryonic stem cell lines derived from human blastocysts. Science 282: $1145-1147$.

Thornberry, N.A. and Lazebnik Y. 1998. Caspases: Enemies within. Science 281: 1312-1316.

Wernig, M., Meissner, A., Foreman, R., Brambrink, T., Ku, M., Hochedlinger, K., Bernstein, B.E., and Jaenisch, R. 2007. In vitro reprogramming of fibroblasts into a pluripotent ES-celllike state. Nature 448: 318-324.

Wysocka, J., Myers, M.P., Laherty, C.D., Eisenman, R.N., and Herr, W. 2003. Human Sin3 deacetylase and trithorax-related Set1/Ash2 histone H3-K4 methyltransferase are tethered together selectively by the cell-proliferation factor HCF-1. Genes Dev. 17: 896-911.

Yokoyama, A., Wang, Z., Wysocka, J., Sanyal, M., Aufiero, D.J., Kitabayashi, I., Herr, W., and Cleary, M.L. 2004. Leukemia proto-oncoprotein MLL forms a SET1-like histone methyltransferase complex with menin to regulate Hox gene expression. Mol. Cell. Biol. 24: 5639-5649.

Yu, J., Vodyanik, M.A., He, P., Slukvin, I.I., and Thomson, J.A. 2006. Human embryonic stem cells reprogram myeloid precursors following cell-cell fusion. Stem Cells 24: 168-176.

Zwaka, T.P. and Thomson, J.A. 2003. Homologous recombination in human embryonic stem cells. Nat. Biotechnol. 21:319321 . 


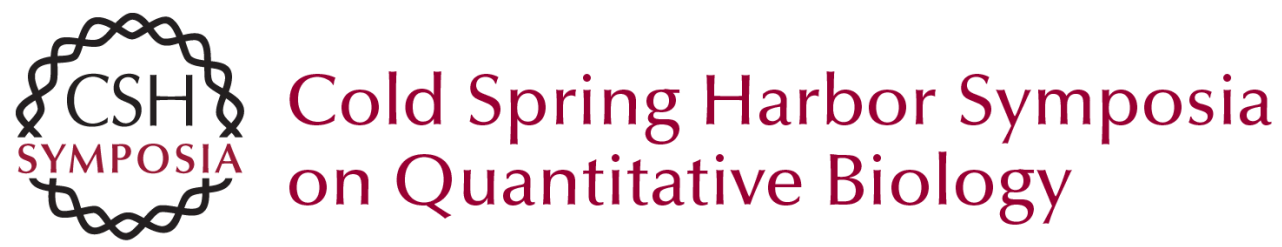

\title{
Ronin and Caspases in Embryonic Stem Cells: A New Perspective on Regulation of the Pluripotent State
}

\author{
T.P. Zwaka
}

Cold Spring Harb Symp Quant Biol 2008 73: 163-169 originally published online November 6, 2008 Access the most recent version at doi:10.1101/sqb.2008.73.007

References This article cites 52 articles, 17 of which can be accessed free at: http://symposium.cshlp.org/content/73/163.full.html\#ref-list-1

\section{License}

Email Alerting Service top right corner of the article or click here. 